\title{
Glycan regulation in cancer, nervous and immune system: A narrative review
}

\author{
Hamad Haider Khan ${ }^{1}$, Bingyin Shi ${ }^{1}$, Yang Tian ${ }^{2}$, Ting Wang ${ }^{3}$, Shida Hussain ${ }^{4}$, Faiz Ullah Khan ${ }^{5,6, * \odot}$, Zakir \\ Khan $^{6,7}$, Beenish Ashfaq ${ }^{6}$, Hussain Ahmad ${ }^{8}$, Tauseef Ahmad $^{9}$
}

${ }^{1}$ Department of Clinical Endocrinology Xian Jiaotong University, First Affiliated Hospital, Xian, Shanxi, China

${ }^{2}$ Associate Chief Physician at Department of Pulmonology Xian Jiaotong University, First Affiliated Hospital, Xian, Shanxi, China

${ }^{3}$ Department of Respiratory Medicine, Xian No.4 Hospital, Xian, PR China

${ }^{4}$ Registrar Nephrology Northwest General Hospital Hayatabad Peshawar, Pakistan

${ }^{5}$ Department of Pharmacy Administration and Clinical Pharmacy, School of Pharmacy, Health Science Centre, Xian Jiaotong

University, Xian, China

${ }^{6}$ Department of Pharmacy Quaid-i-Azam University Islamabad, Pakistan

${ }^{7}$ Department of Pharmacology, Institute of Health Sciences, Cukurova University, Adana, Turkey

${ }^{8}$ The Key Laboratory of Biomedical Information Engineering, Ministry of Education School of Life Sciences and Technology, Xi'an Jiaotong University, Xian, China

${ }^{9}$ Department of Epidemiology and Health Statistics, School of Public Health, Southeast University, Nanjing, (210009), China

\section{Correspondence}

Faiz Ullah Khan, Department of Pharmacy Administration and Clinical Pharmacy, School of Pharmacy, Health Science Centre, Xi'an Jiaotong University, Xian, China

Department of Pharmacy Quaid-i-Azam University Islamabad, Pakistan

Email: fkhan@bs.qau.edu.pk

History

- Received: Feb 10, 2019

- Accepted: Apr 03, 2019

- Published: Apr 30, 2019

DOI :

https://doi.org/10.15419/bmrat.v6i4.536

\section{Check for updates}

\section{Copyright}

(c) Biomedpress. This is an openaccess article distributed under the terms of the Creative Commons Attribution 4.0 International license.

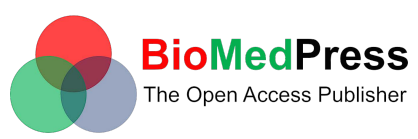

\begin{abstract}
Glycans are carbohydrate components of glycoconjugates, which interact with their receptors; for example, galectins and C-type lectins. The specificity to their receptors makes them the ideal biomarkers that they can be used as a therapeutic target or as a screening tool. We collected and reviewed articles from different databases, which show that glycans play a significant role in several body functions, such as stimulation of the immune system, and can be used in the differentiation among cancer types. They also help in nervous system repair, regeneration, regulation and proliferation. Furthermore, several pathogens like Schistosoma, HIV, Influenza, Candida, and Ebola produce glycoproteins to aid in the invasion via attachment to surface glycoproteins and defend themselves against the host's immune system.

Key words: Glycan, Biomarker Glycoconjugate, Lectins, Immunoglobulin
\end{abstract}

\section{INTRODUCTION}

As characterized by the IUPAC, the terms glycan and polysaccharide are equivalent and describe a compound containing monosaccharides that are connected glycosidically, or bits of carbohydrate glycoconjugates, such as a glycoprotein, glycolipid, or a proteoglycan ${ }^{1}$. Glycans are exclusively comprised of O-glycosidic linkages of monosaccharides. For instance, cellulose is a glycan that is made from $\beta$-1, 4-connected D-glucose, and chitin is a glycan that is made from $\beta$-1,4-connected $\mathrm{N}$-acetylD-glucosamine ${ }^{2-4}$. Glycans can be homo-or heteropolymers of monosaccharide buildups and can be in straight or extended forms. All cells and various macromolecules in nature convey a variety of covalently linked sugars (monosaccharides) or sugar chains (oligosaccharides), which are conventionally alluded to as "glycans" ${ }^{3}$. Sometimes, these glycans can also be freestanding entities. They perform different functions in multicellular organisms and play the role of mediators between different organisms (e.g., between host and a parasite or a symbiont). In addition, protein-bound glycans are abundant within the nucleus and cytoplasm, where they can serve as regulatory switches ${ }^{1}$. During 1960s and 1970s, the initial phase of the molecular biology revolution, investigations of glycans lingered a long way behind those of other major classes of particles. The advancements for studying glycan structures and functions since then opened a novel and new era of molecular biology that was called "glycobiology". In the late 1980s, this word was first coined to distinguish the molecular biology of glycans and specifically, their conjugates with lipids and proteins ${ }^{1}$.

Various natural bioactive molecules are glycoconjugates and linked to glycans, which can affect the biosynthesis, action, stability, and molecules turnover within intact organisms. For instance, heparin (sulfated mucopolysaccharide) and their derivatives are the utmost generally used drugs globally. Glycan biology has turned out to be essential in the current biotechnology because the steps of glycoprotein drug patenting, FDA approval for its usage, and monitoring the overall manufacture require knowledge of the glycan structure. Furthermore, nowadays, glycoproteins are the major products of the biotechnology industry, including monoclonal antibodies, hormones, and enzymes. The diagnostic and/or therapeutic significance of glycans are helpful in several human disease states that are characterized by the changes in glycans biosynthesis ${ }^{5}$.

There are more glycans than proteins encoded in our entire genome. Defects in genes that control glycan production or glycan chaperone proteins, or defects at the level of Golgi-complex, where their assembly occurs, can cause glycosylation disorders ${ }^{6}$. Glycans have a role in protein modification before it is formed as well as when the protein is mature ${ }^{7}$. Because glycan interaction with their receptors is purely physical, 3D analysis of glycoprotein structure via glyco- 
protein crystallography might give better considerate of the contact amongst glycans and their carbohydrate/protein receptors ${ }^{8}$.

Carbohydrates in glycoproteins are attached to their protein part either via $\mathrm{N}$-linked glycosylation, Olinked glycosylation or both ${ }^{9}$. N-linked glycans are made abnormally in cancer cells, which are then recognized by the CD337 receptor on natural killer cells ${ }^{10}$. Glycans can change the function of immunoglobulins. Each immunoglobulin (IgG, IgA, $\operatorname{IgM}$, IgE or $\operatorname{IgD}$ ) has unique properties based on the way it is glycosylated. For example, when IgG $\mathrm{CH} 2-84.4$ glycans are sialylated and fucosylated, it will give that antibody the anti-inflammatory properties, whereas G0 glycan at $\mathrm{CH} 2-84.4$, which lacks galactose and is neither sialylated nor fucosylated, gives the antibody the pro-inflammatory properties, and increases the level of what is seen in various autoimmune diseases ${ }^{11}$. Immune systems have glycan binding receptors, which are known as lectins. These can be secreted, such as galectins, or membranebound like siglecs. Regardless of their locations, all lectins have carbohydrate-recognition domains (CRDs) that bind to the glycan portion of glycoconjugates such as glycoprotein, glycolipid, and proteogly$\mathrm{can}^{12}$. A macrophage galactose-type lectin (MGL), which is expressed exclusively on immature dendritic cells and macrophages, is an example of specific lectins ${ }^{13}$.

Glycosylation is an important post-translational modification, and almost half of all proteins are glycosylated ${ }^{14}$. Glycosylation can act as a key regulatory mechanism controlling several physiopathological processes, and different types of glycosylation can interfere with cell development as well as the microenvironment, which can then lead to cancer formation and progression.

\section{GLYCANS REGULATION IN DIFFERENT SYSTEMS}

\section{Glycosylation Alteration in Cancer}

For almost six decades, it has been known that cancer cells show alterations in glycosylation ${ }^{15}$, but very little is acknowledged about their role in cancer progression and metastasis, or their correlation with the survival rates. However, with the invention of monoclonal antibody technology, which demonstrated that glycans were the target of tumor-specific antibodies, and the recent focus on glycans in the field of cancer research, significant advancements have been made giving much more understanding of tumors' glycoproteins and the significance of glycosphingolipid alterations ${ }^{4}$.
Tumor cells show different forms of glycosylation alterations when compared with their neighboring healthy cells. Glycosylation of proteins increases diversity in their functions while very few changes are imposed on cell structure. These alterations occur at specific locations on the protein and in specific cells. Changes in the specificity of glycosylation in healthy cells are different from glycosylation in cancerous cells, and one or more factors may be involved in these changes in cancer cells ${ }^{16}$.

Glycosylation can occur through altered expression of the enzyme (glycosyltransferase) responsible for catalyzing the addition of carbohydrates onto the protein (glycosylation) at the gene level ${ }^{17}$, or through the defects in the Golgi apparatus where this assembly occurs $^{18}$. Chaperone dysfunction can also lead to the glycosylation changes seen in malignant cells ${ }^{19}$. Most common glycosylation changes seen in cancer cells are fucosylation, sialylation, and $\mathrm{N}$ - and $\mathrm{O}$ - linked branching glycan. Genetic, epigenetic and several environmental factors may be responsible for these changes seen in malignantly transformed cells ${ }^{20}$.

\section{Glycan's Role in Lung Cancer}

Acute phase proteins undergo glycosylation in inflammation and cancer. Changes in glycosylation are correlated with the severity of the disease. A1AT ( $\alpha$ 1 -antitrypsin) is an example, whose primary function is to regulate protease/anti-protease activity. It also has a role in cancer, as the altered glycosylation of A1AT is seen in lung, liver, breast, and prostate cancer ${ }^{21}$.A1AT can be used in cancer detection and differentiation: the glycosylated patterns of A1AT may help in detection of lung cancer as galactosylated A1AT can distinguish NSCLC (nonsmall-cell lung cancer) from benign pulmonary diseases, while fucosylated A1AT can differentiate ADC (adenocarcinoma) from other types of lung cancers and A1AT-containing poly-LacNAc is useful in detection of SCLC ${ }^{22}$. Several NSCLC (non-small-cell lung cancer)-specific glycoproteins and their $\mathrm{N}$-linked glycosylation sites have been identified, and these can increase the specificity of thoracic CT scans conducted to detect lung cancers ${ }^{23}$. The pulmonary surfactant's main components, or SP-A (lung surfactant protein A), interacts with macrophages or monocytes and is uptaken by macrophages and transported into secondary lysosomes. This uptake is inhibited by alpha-D-mannosyl-bovine serum albumin (BSA), but not by beta-D-galactosyl-BSA. SP-A is a glycoprotein with $\mathrm{N}$-glycosylated glycans, so it could act as a ligand for the mannose-specific receptor on macrophages. 
As SP-A is a mannose-specific lectin itself, it can bind to mannose residues on cell surface of marcrophages $^{24}$.

One study showed that cigarette smoking leads to increased expression of the receptor for advanced glycation end-products (RAGE) involved in the activation of NF- $\kappa \mathrm{B}$, which is mediated by Ras, leading to inflammatory lung disease ${ }^{25}$.Protein glycosylation affects protein folding, functionality, and stability. Abnormally glycosylated protein aids in malignant transformation of tumor cells. Lung cancer expresses sialylated or fucosylated glycans on their cell surfaces, including, Globo H, sialyl Lewis x (sLex), sialyl Tn (sTn), Lewis y (Ley) and polysialic acid ${ }^{26}$.EGFR (epidermal growth factor receptor), a glycoprotein, has tyrosine kinase activity. EGFR is over-expressed in cancer cells, which supports cancer cell invasion, metastasis, and angiogenesis. Twelve glycosylation sites are known to exist on EGFR extracellular region and glycosylation may help to regulate some of EGFR functions. CL1-0 and CL1-5 are two distinct cell lines derived from lung cancers, each holding distinct invasive properties with high sialylation and fucosylation of EGFR. Sialylation and fucosylation could modulate EGFR-mediated lung cancer invasiveness. Increased sialylation and fucosylation downregulate EGFR, thus leading to lower lung cancer cell metastasis, while facilitating incorporation of the core fucose via $\alpha$ 1,6-fucosyltransferase, which upregulates EGFR, leads to greater cancer metastasis. This may also be the mechanism behind cancer cell resistance to EGFR inhibitors ${ }^{27}$. Beta-glycan, which is also known as Type III TGF- $\beta$ receptor or RIII, is a proteoglycan. Its expression is controlled by TGF- $\beta 1$ (transforming growth factor beta). TGF- $\beta 1$ is an inhibitor of growth even though small cell lung cancer (SCLC) seems to be resistant to its growth inhibiting properties due to lacking the expression of R1, R2 TGF- $\beta$ receptor proteins $^{28}$. Another study indicates that only the lack of R2 receptors might explain cancer cell resistance to TGF- $\beta^{29}$.

Haptoglobin is an acute phase protein. It is made in the liver and is regulated by several cytokines ${ }^{30}$.Its two glycoforms, sialylated and fucosylated haptoglobins, can potentially serve as biomarkers for NSCLC ${ }^{31}$.P-selectin, which is a transmembrane adhesion receptor present at Weibel Palade bodies of endothelial-cells and alpha-granules of platelets, binds to the glycans of neutrophils and monocytes containing sialyl-Lewis X antigens ${ }^{32}$. Higher sialylation of the glycoprotein P-selectin has been observed in cancer cells, and P-selectin was suggested to aid in cancer invasion and metastasis ${ }^{33}$.In one experiment, lung metastasis of the colon cancer was prevented by inhibiting sialyltransferase, indicating the role of $\mathrm{P}$ selectin in metastasis ${ }^{34}$.

\section{Glycans and the Role in Cancer Diagnosis}

Early detection of cancer is the main factor in fighting against this ever-evolving disease. Glycans have the potential to act as noninvasive biomarkers that can detect cancer before it metastasizes, which helps to monitor malignant progression, and accurately predict prognosis ${ }^{35}$. One successful example of a glycobiomarker is AFP (alpha-fetoprotein), a glycoprotein made during embryogenesis and fetal development that is currently used for the detection of hepatocellular carcinoma (HCC) ${ }^{36}$. However, AFP is not very useful in differentiating benign liver disease from HCC. Fucosylated AFP-L3 fraction, on the other hand, appears in the serum of a patient with cirrhosis just before its malignant transformation to cancer, thus making it an ideal glycobiomarker in diagnosis $^{37}$. Beta-HCG (beta-human chorionic gonadotropin), which is used in gynecological malignancy monitoring; or PSA (prostate-specific antigen) in prostate cancer, and Dx and CEA (carcinoembryonic antigen) in colon cancer monitoring, are all examples of glycol biomarkers that are used today ${ }^{38}$. The EML4 ALK [Echinoderm Microtubule linked protein as 4(EML4), ALK (Anaplastic Lymphoma Kinase)] and KRAS (V- Ki-ras2 Kirsten rat sarcoma homolog viral oncogene) are other examples of glycol biomarkers used for lung cancer detection ${ }^{39}$. Further discovery of more glycol biomarkers that are able to detect cancer in its early stages will contribute greatly to lowering cancer-related deaths, provide more accurate prognosis and diagnosis of cancers, and will facilitate the differentiation of cancer types ${ }^{40}$.

\section{Glycan and the Role in Cancer Treatment}

Cancers are defined as a diseases group, which involves irregular cell development and the ability to occupy other areas of the body ${ }^{41,42}$. PTMs (posttranslation modifications) such as methylation, Nacetylation, phosphorylation, and glycosylation are involved in the maintenance of proteins functioning in both cancer and normal cells. Most commonly occurring PTMs is glycosylation, and is involved in various biological mechanisms ${ }^{41,43}$.

Glycans are the essential biosynthetic precursors and attached to lipids or proteins to form glycoproteins or glycolipids as structural elements ${ }^{41}$. As an important factor in the understanding of different cancer mechanisms, diagnostic and therapeutic strategies, glycan 
biology has gained an important part in cancer research $^{42}$. Glycan also act as a key regulatory mechanism of several physio-pathological processes ${ }^{44}$. It was reported over more than sixty years ago that glycosylation changes associated with cancer transformation $^{42}$. A wide range of glycosylation alternations was displayed by cancerous cells as compared to their non-transformed complements. Molecular heterogeneity and functional diversity within cell populations increased due to glycosylation ${ }^{16,42}$.

Nowadays, new strategies and options are urgently needed for timely diagnosis, risk assessment and treatments of cancer, and glycans can be a potential source for the development of new biomarkers. Glycoproteins are the most common used serological biomarkers for clinical diagnosis, monitoring of progression and prognostic of disease recurrence in cancers $^{35,41,42}$. Different types of prominent biomarkers used in patients with prostate, ovarian, colon, breast, gastric and pancreatic cancer ${ }^{42}$. These biomarkers have been shown with abnormal glycosylation in cancer cells. The use of these biomarkers for screening and diagnostic strategies are low due to their low specificity. Therefore, new research and strategies of higher specificity biomarkers are required for the early detection and diagnosis of cancers. For example, $\alpha$-fetoprotein (AFP) is a glycol-biomarker, which is used for the detection of liver diseases and is a generally validated protein for the diagnosis of Hepatocellular carcinoma (HCC). However, serum levels of AFP does not differentiate between HCC and benign liver diseases. Therefore, the glycosylated form of AFP (AFP-L3 fraction) was proposed as an additional cancer marker, that shows significant results to compare HCC patients and chronic liver diseases ${ }^{42,45}$.

Glycosylated proteins and other glycoconjugates are involved in several important physiological processes in normal tissues and act as major components of cells. Modifications of glycosylation occurred due to metabolic, genetic, epigenetic, inflammatory and environmental mechanisms that initiate various biological processes in cancer ${ }^{41}$. The new knowledge and understanding in the glycobiology would provide rapid expansion of novel glycoengineered and model platforms. The combination of the increasing data and recent advances in glycomics, glycoproteomics, genomics, metabolomics and proteomics will provide novel targets and fruitful strategies for the timely diagnosis, prognosis and improved treatments of cancers. In short, a better understanding of abnormal glycan mechanisms is important for the design and synthesis of anti-cancer drugs ${ }^{41-43}$.

\section{The Role of Glycans in the Nervous System}

Glycans have important functions in nervous system development, regeneration, and maintenance of its plasticity ${ }^{46}$. Oligodendrocytes express an extracellular glycoprotein tenascin-R, which is only found in the central nervous system of vertebrates, can support axon regeneration and remyelination. Phosphacan, Aggrecan, Versican, Neurocan, Brevican are the ligands to which tenascin- $R$ attaches, and they play an important role in synaptogenesis, neural cell adhesion and migration ${ }^{47}$. One of the most common posttranslational modifications of proteins is $\mathrm{N}$ Glycosylation, which plays an important role in the central nervous system. For example, it is active in the biosynthesis of ganglioside, which is regulated by glycosyltransferases. Cells can switch between expressing simple and complex gangliosides, or in between simple and complex gangliosides during the development of the brain. However, glycosyltransferases need to be fine-tuned at the subcellular level and stated in a precise way in the biosynthesis of gangliosides in parallel enzymatic pathways ${ }^{48}$.

CNS recovery can be halted if reactive astrocytes produce chondroitin sulfate proteoglycan, which acts to inhibit axonal regeneration. Lectin-glycan interaction was suggested to play an important role in NSC (Neural Stem Cell) regulation and proliferation due to the glycan binding ability of Galectin-1 in the extracellular matrix ${ }^{49}$.

\section{The Role of Glycans in the Immune System and Autoimmunity}

The immune system of human is presented every day with the challenging task of differentiating the 'self' from the invaders and the cells that have gone cancerous. The immune system does this via an intricate system; if anything in this system goes wrong, it could lead to autoimmunity ${ }^{50}$. One area in which the immune system must discriminate antigens is with gut microbiota. There are 10 bacterial cells for every human cell, with more than 10,000 species of bacterial cells. Collectively they constitute $1-3 \%$ of human body weight, and yet we know very little about how these microorganisms exist in harmony with their host. Recent studies have shown that glycoconjugates may be behind such host-microbial relationships. For example, if Helicobacter pylori bind to a fucosylated or sialylated glycans, this will prime to the activation of the defense in the immune system. However, Bacteroides, a normal flora of the gut, can attach to fucosylated glycans without activating similar response ${ }^{51}$. 
The controlled expressions of glycans on the cell surface through the enzymes glycosyltransferase and glycosidase, both of which modify glycans, are vital in immune cell activation and homeostasis. Galectin, a family of lectins, is expressed by almost all immune cells, either continuously or in inducible forms. It can be upregulated by other immune cells such as activated $\mathrm{B}$ and $\mathrm{T}$ cells. All galectins have at least one CRD (carbohydrate receptor domain) that binds to glycan. Galectins upregulation has been observed in many tumors. Prostate cancer cells that express a low level of the glycosyltransferase GCNT1, are resistant to apoptosis mediated by galectin 1 , but they express a high enough level of glycosyltransferase GCNT1 to eliminate effector $\mathrm{T}$ cells ${ }^{52}$. Changes in the tri- and tetra-antennary glycan structures, sialyl Lewis X epitopes and galactosylated bi-antennary glycans, are observed in cancer patients, and many of these changes in chronic inflammatory diseases have also been observed $^{53}$.

Systemic lupus erythematous (SLE), rheumatoid arthritis, Crohn's disease, and other autoimmune diseases are known to have altered patterns of glycosylation of glycoprotein $\operatorname{IgG}^{54}$. Decreased galactosylation and sialylation of the $\mathrm{Fc}$ region have also been observed in autoimmune diseases ${ }^{55}$. In fact, IgG can be switched between its anti-inflammatory and proinflammatory properties depending on the degree of its sialylation ${ }^{56}$. Streptococcus pyogenes has an Endos (endoglycosidase) that hydrolyzes asparaginelinked glycan on IgG, which acts to render IgG inactivity so that it can no longer bind to $\mathrm{Fc} \gamma \mathrm{R}$ on white blood cells and trigger an immune response ${ }^{57}$.

The influenza virus that killed over 50 million people in just one year in the ' $90 \mathrm{~s}^{58}$ also attached to its host via a glycan with an sialic acid on its end by using a glycoprotein known as Hemagglutinin (HA). This interaction of HA and glycan was critical in the infectivity and transmission of the influenza virus ${ }^{59}$. Its specificity depends on the fucosylation, sulfation, and sialylation of the host receptors, as well as the type of linkage possessed by sialic acid. The human influenza virus binds to $\alpha$ 2-6 linked sialic acid located on the respiratory tract epithelium makeing it different from the avian influenza virus binding site, which binds to $\alpha$ 2-3 linked sialic acid located on the epithelium of intestinal tract ${ }^{60}$. Though H5N1 virus binds to $\alpha 2-3$ sialylated glycan, some mutant strains have been observed binding to $\alpha$ 2-6 sialylated glycan, which can lead to human adaptation of this strain ${ }^{61}$.

HIV interaction with its human host is also dependent on a glycoprotein, gp120, which is a viral protein used by HIV to bind to the host's CD4+ve T- cells $^{62}$. There are contrary data on whether carbohydrates play a role in this interaction. Glycans' role in escaping the host's defense system is not limited to HIV; other viruses and parasites also use them in to fight against the host defense system ${ }^{63}$. HIV and Ebola viruses bind to DC-SIGN(R) (dendritic cellspecific ICAM-3 grabbing nonintegrin)(receptor) on host cell surfaces via glycoproteins present on their envelope ${ }^{64}$. Candida albicans also produce glycans that recognize DC-SIGN(R) via $\alpha$-Man ${ }^{65}$.

Our immune system can use the same glycans to recognize foreign invaders. For example, Schistosoma and other helminths produce glycans that can trigger an immune response ${ }^{66}$.

\section{CONCLUSION}

There is an increasing need to study glycan and its interaction with receptors as they are involved in many functions in the human body. Thus, it is impossible to ignore its future role in medicine.

Recent advancements in deciphering the information about glycan receptor interactions have led to an understanding that glycan binding receptors (galectins, siglecs) and their interaction with glycan play a significant role in immunity, autoimmunity, homeostasis, and cancers. Researchers only have the faintest glimmer of knowledge concerning the possible role of glycan in disease development and progression. Future measures are needed to take what is known about protein-saccharide interaction to develop effective treatments for diseases for which there are currently no cures. These include various autoimmune diseases, cancer, and chronic inflammation. The impressive progress over the recent years in understanding glycans as promising biomarkers in cancers has contributed to the discovery of glycans and their importance to clinical applications as potential targets for personalized and individualized medicine.

\section{ABBREVIATIONS}

NSCLC: Non-small cell lung cancer

A1AT: $\alpha$-1-antitrypsin

SCLC: small cell lung-cancer

ADC: adenocarcinoma

PSA: prostate-specific antigen,

AFP: alpha-fetoprotein,

HCC: Hepatocellular carcinoma

NSC: Neural Stem Cell

EndoS: endoglycosidase

EGFR: epidermal growth factor receptor

DC-SIGN(R): dendritic cell-specific ICAM (intercellular adhesion molecule)-grabbing nonintegrin

TGF- $\beta$ 1: transforming growth factor beta

HIV: Human immunodeficiency virus 


\section{AUTHORS' CONTRIBUTIONS}

All authors equally contributed to this review.

HHK conceptualized the idea and collected the data with the help of YT, TW and TA, BA, HA, ZK review edited and approved the manuscript. The final manuscript was reviewed by FUK and AUR.

\section{COMPETING INTERESTS}

Authors declare no conflict of interest

\section{ACKNOWLEDGMENT}

We owe to thanks all the contributors who support and guide us throughout the manuscript.

\section{REFERENCES}

1. Varki A, Sharon N. Historical background and overview. In: Essentials of Glycobiology 2nd edition. Cold Spring Harbor Laboratory Press; 2009.

2. Sahoo SS, Thomas C, Sheth A, Henson C, York WS. GLYDEan expressive XML standard for the representation of glycan structure. Carbohydrate research. 2005;p. 2802-7. 16242678. Available from: 10.1016/j.carres.2005.09.019.

3. Varki A. Evolutionary forces shaping the Golgi glycosylation machinery: why cell surface glycans are universal to living cells. Cold Spring Harbor perspectives in biology. 2011;3(6):a005462. 21525513. Available from: 10.1101/ cshperspect.a005462.

4. Astronomo RD, Burton DR. Carbohydrate vaccines: developing sweet solutions to sticky situations? Nature reviews. Drug;2010(9). 20357803. Available from: 10.1038/nrd3012.

5. Kiessling LL, Splain RA. Chemical approaches to glycobiology. Annual review of biochemistry. 2010;79:619-53. 20380561. Available from: 10.1146/annurev.biochem.77.070606.100917.

6. Freeze HH. Genetic defects in the human glycome. Nat Rev Genet. 2006;7(7):537-51. 16755287. Available from: 10.1038/ nrg1894.

7. Helenius A, Aebi M. Intracellular functions of N-linked glycans. Science. 2001;291(5512):2364-9. 11269317. Available from: 10.1126/science.291.5512.2364.

8. Nagae $M$, Yamaguchi Y. Function and 3D structure of the $N$ glycans on glycoproteins. International journal of molecular sciences. 2012;13(7):8398-429.

9. Spiro RG. Protein glycosylation: nature, distribution, enzymatic formation, and disease implications of glycopeptide bonds. Glycobiology. 2002;12(4):43R-56R. 12042244. Available from: 10.1093/glycob/12.4.43R.

10. Parsons IC, Bulik DA, Bosques CJ, Thiruneelakantapillai $L$, Collins BE. Characterization of N-glycans using exoglycosidases. Google Patents. 2013;

11. Maverakis E, Kim K, Shimoda M, Gershwin ME, Patel F, Wilken $\mathrm{R}$, et al. Glycans in the immune system and The Altered Glycan Theory of Autoimmunity: a critical review. Journal of autoimmunity. 2015;57:1-13. 25578468. Available from: 10.1016/j.jaut.2014.12.002.

12. van Kooyk Y, Rabinovich GA. Protein-glycan interactions in the control of innate and adaptive immune responses. Nat Immunol. 2008;9(6):593-601. 18490910. Available from: 10. 1038/ni.f.203.

13. van Vliet SJ, Saeland E, van Kooyk Y. Sweet preferences of MGL: carbohydrate specificity and function. Trends in immunology. 2008;29(2):83-90. 18249034. Available from: 10.1016/j.it.2007.10.010.

14. Zhao YY, Takahashi M, Gu JG, Miyoshi E, Matsumoto A, Kitazume $\mathrm{S}$, et al. Functional roles of $\mathrm{N}$-glycans in cell signaling and cell adhesion in cancer. Cancer science. 2008;99(7):130410. 18492092. Available from: 10.1111/j.1349-7006.2008. 00839.x.
15. Rachagani S, Torres MP, Moniaux N, Batra SK. Current status of mucins in the diagnosis and therapy of cancer. Biofactors. 2009;35(6):509-27. 19904814. Available from: 10.1002/biof. 64.

16. Kannagi R, Yin J, Miyazaki K, Izawa M. Current relevance of incomplete synthesis and neo-synthesis for cancer-associated alteration of carbohydrate determinants-Hakomori's concepts revisited. Biochimica et Biophysica Acta (BBA)-General Subjects. 2008;1780(3):525-31. 17980710. Available from: 10.1016/j.bbagen.2007.10.007.

17. Stowell SR, Ju T, Cummings RD. Protein glycosylation in cancer. Annual Review of Pathology: Mechanisms of Disease. 2015;10:473-510. 25621663. Available from: 10.1146/ annurev-pathol-012414-040438.

18. Gill DJ, Chia J, Senewiratne J, Bard F. Regulation of Oglycosylation through Golgi-to-ER relocation of initiation enzymes. The Journal of cell biology. 2010;189(5):843-58. 20498016. Available from: 10.1083/jcb.201003055.

19. Schietinger A, Philip M, Yoshida BA, Azadi P, Liu H, Meredith SC. A mutant chaperone converts a wild-type protein into a tumor-specific antigen. Science. 2006;314(5797):3048. 17038624. Available from: $10.1126 /$ science. 1129200.

20. Varki A, Kannagi R, Toole BP. Glycosylation changes in cancer. In: Varki A, Cummings RD, Esko JD, Freeze HH, Stanley P, Bertozzi CR, et al., editors. Essentials of Glycobiology. NY: Cold Spring Harbor Laboratory Press; 2009. .

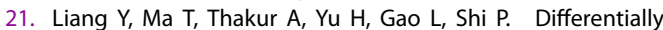
expressed glycosylated patterns of $\alpha$-1-antitrypsin as serum biomarkers for the diagnosis of lung cancer. Glycobiology. 2015;25(3):331-40. 25347993. Available from: 10.1093/ glycob/cwu115.

22. Liang $Y$, Ma T, Thakur A, Yu H, Gao L, Shi P. Differentially expressed glycosylated patterns of $\alpha$-1-antitrypsin as serum biomarkers for the diagnosis of lung cancer. Glycobiology. 2015;25(3):331-40. 25347993. Available from: 10.1093/ glycob/cwu115.

23. Zeng X, Hood BL, Sun M, Conrads TP, Day RS, Weissfeld JL. Lung Cancer Serum Biomarker Discovery Using Glycoprotein Capture and Liquid Chromatography Mass Spectrometry. Journal of Proteome Research. 2010;9(12):6440-9. 20931982. Available from: 10.1021/pr100696n.

24. Hickman-Davis JM, Fang FC, Nathan C, Shepherd VL, Voelker $\mathrm{DR}$, Wright JR. Lung surfactant and reactive oxygen-nitrogen species: antimicrobial activity and host-pathogen interactions. American journal of physiology-lung cellular and molecular physiology. 2001;281(3):L517-L23. 11504674. Available from: 10.1152/ajplung.2001.281.3.L517.

25. Reynolds PR, Kasteler SD, Schmitt RE, Hoidal JR. Receptor for advanced glycation end-products signals through Ras during tobacco smoke-induced pulmonary inflammation. American journal of respiratory cell and molecular biology. 2011;45(2):411-8. 21131443. Available from: $10.1165 / \mathrm{rcmb}$. 2010-0231OC.

26. Dube DH, Bertozzi CR. Glycans in cancer and inflammationpotential for therapeutics and diagnostics. Nature reviews Drug discovery. 2005;4(6):477. 15931257. Available from: 10.1038/nrd1751.

27. Ying-Chih Liua b, 1. Sialylation and fucosylation of epidermal growth factor receptor suppress its dimerization and activation in lung cancer cells;

28. Favoni RE, De Cupis A. The role of polypeptide growth factors in human carcinomas: new targets for a novel pharmacological approach. Pharmacological reviews. 2000;52(2):179-206. 10835099.

29. Swann JB, Smyth MJ. Immune surveillance of tumors. The Journal of clinical investigation. 2007;117(5):1137-46. 17476343. Available from: 10.1172/JCI31405.

30. Bode JG, Albrecht U, Häussinger D, Heinrich PC, Schaper F. Hepatic acute phase proteins-regulation by IL-6-and IL1-type cytokines involving STAT3 and its crosstalk with NF$\kappa \mathrm{B}$-dependent signaling. European journal of cell biology. 
2012;91(6-7):496-505. 22093287. Available from: 10.1016/j. ejcb.2011.09.008.

31. Hoagland LF, Campa MJ, Gottlin EB, 2nd Herndon JE, Jr Patz EF. Haptoglobin and posttranslational glycan-modified derivatives as serum biomarkers for the diagnosis of nonsmall cell lung cancer. Cancer. 2007;110(10):2260-8. 17918261. Available from: $10.1002 / \mathrm{cncr} .23049$.

32. Cummings RD, McEver RP. C-type lectins. Essentials of Glycobiology. 2nd ed. NY: Cold Spring Harbor Laboratory Press; 2009.

33. Wang PH. Altered glycosylation in cancer: sialic acids and sialyltransferases. J Cancer Mol. 2005;1(2):73-81.

34. Kannagi R, Izawa M, Koike T, Miyazaki K, Kimura N. Carbohydrate-mediated cell adhesion in cancer metastasis and angiogenesis. Cancer science. 2004;95(5):377-84. 15132763. Available from: 10.1111/j.1349-7006.2004.tb03219.x.

35. Reis CA, Osorio H, Silva L, Gomes C, David L. Alterations in glycosylation as biomarkers for cancer detection. Journal of clinical pathology. 2010;63(4):322-9. 20354203. Available from: 10.1136/jcp.2009.071035.

36. Kim YS, Yoo HS, Ko JH. Implication of aberrant glycosylation in cancer and use of lectin for cancer biomarker discovery. Protein and peptide letters. 2009;16(5):499-507. 19442229. Available from: 10.2174/092986609788167798.

37. Tateishi R, Yoshida H, Matsuyama Y, Mine N, Kondo Y, Omata M. Diagnostic accuracy of tumor markers for hepatocellular carcinoma: a systematic review. Hepatology international. 2008;2(1):17-30. 19669276. Available from: 10.1007/s12072007-9038-x.

38. Gilgunn S, Conroy PJ, Saldova R, Rudd PM, O'Kennedy RJ. Aberrant PSA glycosylation-a sweet predictor of prostate cancer. Nature Reviews Urology. 2013;10(2):99-107. 23318363. Available from: 10.1038/nrurol.2012.258.

39. West L, Vidwans SJ, Campbell NP, Shrager J, Simon GR, Bueno $\mathrm{R}$, et al. A novel classification of lung cancer into molecular subtypes. PLoS One. 2012;7(2):e31906. 22363766. Available from: 10.1371/journal.pone.0031906.

40. Pinho SS, Reis CA. Glycosylation in cancer: mechanisms and clinical implications. Nature Reviews Cancer. 2015;15(9):54055. 26289314. Available from: 10.1038/nrc3982.

41. Li X, Wang X, Tan Z, Chen S, Guan F. Role of glycans in cancer cells undergoing epithelial-mesenchymal transition. Frontiers in oncology. 2016;6:33. 26925388. Available from: 10.3389/fonc.2016.00033.

42. Pinho SS, Reis CA. Glycosylation in cancer: mechanisms and clinical implications. Nature Reviews Cancer. 2015;15(9):540. 26289314. Available from: 10.1038/nrc3982.

43. Tan Z, Lu W, Li X, Yang G, Guo J, Yu H, et al. Altered N-Glycan expression profile in epithelial-to-mesenchymal transition of NMUMG cells revealed by an integrated strategy using mass spectrometry and glycogene and lectin microarray analysis. Journal of proteome research. 2014;13(6):2783-95. 24724545. Available from: 10.1021/pr401185z.

44. Moremen KW, Tiemeyer M, Nairn AV. Vertebrate protein glycosylation: diversity, synthesis and function. Nature reviews Molecular cell biology. 2012;13(7):448. 22722607. Available from: 10.1038/nrm3383.

45. Sato Y, Nakata K, Kato Y, Shima M, Ishii N, Koji T, et al. Early recognition of hepatocellular carcinoma based on altered profiles of alpha-fetoprotein. New England Journal of Medicine. 1993;328(25):1802-6. 7684823. Available from: 10.1056/NEJM199306243282502.

46. Kleene R, Schachner M. Glycans and neural cell interactions. Nat Rev Neurosci. 2004;5(3):195-208. 14976519. Available from: $10.1038 / \mathrm{nrn} 1349$.

47. Pesheva P, Probstmeier R. The yin and yang of tenascin-R in CNS development and pathology. Progress in Neurobiology. 2000;61(5):465-93. 10748320. Available from: 10.1016/S03010082(99)00061-1.

48. Robert KY, Bieberich E, Xia T, Zeng G. Regulation of ganglioside biosynthesis in the nervous system. Journal of lipid re- search. 2004;45(5):783-93. 15087476. Available from: 10 . 1194/jlr.R300020-JLR200.

49. Okano H, Sakaguchi M, Ohki K, Suzuki N, Sawamoto K. Regeneration of the central nervous system using endogenous repair mechanisms. Journal of neurochemistry. 2007;102(5):1459-65. 17697047. Available from: 10.1111/j. 1471-4159.2007.04674.x.

50. Rabinovich GA, Croci DO. Regulatory circuits mediated by lectin-glycan interactions in autoimmunity and cancer. Immunity. 2012;36(3):322-35. 22444630. Available from: 10 . 1016/j.immuni.2012.03.004.

51. Hooper LV, Gordon J. Glycans as legislators of hostmicrobial interactions: spanning the spectrum from symbiosis to pathogenicity. Glycobiology. 2001;11(2):1R-10R. 11287395. Available from: 10.1093/glycob/11.2.1R.

52. Rabinovich GA, Toscano MA. Turning 'sweet' on immunity: galectin-glycan interactions in immune tolerance and inflammation. Nat Rev Immunol. 2009;9(5):338-52. 19365409. Available from: 10.1038/nri2536.

53. Arnold JN, Saldova R, Hamid UMA, Rudd PM. Evaluation of the serum n-linked glycome for the diagnosis of cancer and chronic inflammation. Proteomics. 2008;8(16):3284-93. 18646009. Available from: 10.1002/pmic.200800163.

54. Goulabchand R, Vincent T, Batteux F, Eliaou Jf, Guilpain P. Batteux F, Eliaou J-f, Guilpain P. Impact of autoantibody glycosylation in autoimmune diseases. Autoimmunity reviews. 2014;13(7):742-50. 24657512. Available from: 10.1016/j. autrev.2014.02.005.

55. Nimmerjahn F. editor Activating and inhibitory Fc $\gamma$ Rs in autoimmune disorders. In: and NF, editor. Springer seminars in immunopathology. Springer; 2006. .

56. Kaneko Y, Nimmerjahn F, Ravetch JV. Anti-inflammatory activity of immunoglobulin $G$ resulting from Fc sialylation. Science. 2006;313(5787):670-3. 16888140. Available from: 10. $1126 /$ science. 1129594 .

57. Allhorn M, Olin Al, Nimmerjahn F, Collin M. Human lgG/Fc $\gamma R$ interactions are modulated by streptococcal IgG glycan hydrolysis. PloS one. 2008;3(1):e1413. 18183294. Available from: 10.1371/journal.pone.0001413.

58. Johnson NP, Mueller J. Updating the accounts: global mortality of the 1918-1920" Spanish" influenza pandemic. Bulletin of the History of Medicine. 2002;76(1):105-15. 11875246. Available from: 10.1353/bhm.2002.0022.

59. Viswanathan K, Chandrasekaran A, Srinivasan A, Raman R, Sasisekharan V, Sasisekharan R. Glycans as receptors for influenza pathogenesis. Glycoconjugate journal. 2010;27(6):561-70. 20734133. Available from: 10.1007/ s10719-010-9303-4.

60. Stencel-Baerenwald JE, Reiss K, Reiter DM, Stehle T, Dermody TS. The sweet spot: defining virus-sialic acid interactions. Nature Reviews Microbiology. 2014;12(11):739-49. 25263223. Available from: $10.1038 / \mathrm{nrmicro} 3346$.

61. Stevens J, Blixt O, Chen LM, Donis RO, Paulson JC, Wilson IA. Recent avian H5N1 viruses exhibit increased propensity for acquiring human receptor specificity. Journal of molecular biology. 2008;381(5):1382-94. 18672252. Available from: 10.1016/j.jmb.2008.04.016.

62. Arthos J, Cicala C, Martinelli E, Macleod K, Ryk DV, Wei D, et al. HIV-1 envelope protein binds to and signals through integrin $\alpha 4 \beta$, the gut mucosal homing receptor for peripheral T cells. Nature immunology. 2008;9(3):301. 18264102. Available from: 10.1038/ni1566.

63. Kreisman LS, Cobb BA. Infection, inflammation and host carbohydrates: a Glyco-Evasion Hypothesis. Glycobiology. 2012;22(8):1019-30. 22492234. Available from: 10.1093/ glycob/cws070.

64. Lin G, Simmons G, Pöhlmann S, Baribaud F, Ni H, Leslie GJ. Differential N-linked glycosylation of human immunodeficiency virus and Ebola virus envelope glycoproteins modulates interactions with DC-SIGN and DC-SIGNR. Journal of virology. 2003;77(2):1337-46. 12502850. Available from: 10.1128/JVI. 
77.2.1337-1346.2003.

65. Poulain D, Jouault T. Candida albicans cell wall glycans, host receptors and responses: elements for a decisive crosstalk. Current opinion in microbiology. 2004;7(4):342-9. 15358252. Available from: 10.1016/j.mib.2004.06.011.
66. van Die I, Cummings RD. Glycans modulate immune responses in helminth infections and allergy. Parasites and allergy. In: Parasites and allergy. Karger Publishers; 2006. p. $91-$ 112. 